dependently, and that we know nothing about the inheritance of piety and freedom, either separately or in Germanic linkage. The writer wishes also to apologize for being compelled to point out that it is not good biology to maintain that the oblique eyes of the Chinese or Japanese are an indication of an oblique character, or that in a hybrid the "bad" qualities of the parents are dominant over the "good" ones.

5. While the statements of the war enthusiasts will not be taken seriously by those familiar with the methods and results of experimental biology, the sad fact remains that this pseudobiology has had at least a share in the production of the tragedy which is being enacted in Europe. For wars are impossible unless the masses are aroused to a state of emotionalism and fanaticism, and the pseudobiology of literateurs and politicians may serve this purpose in the future as it has in the past. The government has at last begun to realize that it is its duty to protect the masses from the medical quack. Your speaker is of the opinion that the masses need equal protection from the irresponsible literateur or politician who makes it his business to spread the seed of fanaticism and emotionalism by a claim of knowledge of biology which he does not possess. The cure for this form of pernicious mischief is the spread of knowledge of the exact sciences which will put an end to the business of the pseudoscientist.

Since at present the making of war is left in the hands of the statesmen, it may be well to mention at least that the exact sciences have paved the way for the replacement of the present type of statesmanship by a new one; according to which statesmanship consists in the application of the results of the exact sciences to the improvement of the lot of humanity. This includes not only the technical but also the theoretical results of science, since these theoretical results will free the minds from all those forms of ignorance, superstition and fanaticism which are the culture medium of mob emotionalism. If we succeed in substituting for the present a new type of statesmen, who are familiar with and follow the development of the exact$i$. e., the experimental and quantitativesciences, and who are willing and capable of applying the results of exact science to the intellectual, moral, physical and economical uplift of the masses, we shall at least diminish the danger of war.

THE ROCKEFELLER INSTITUTE FOR

JACQUES LOEB

Medical Research, NEW YoRK

\section{ASYMMETRIC SYNTHESES AND THEIR BEARING ON THE DOCTRINE OF VITALISM. II}

The fact that an asymmetric compound prepared in the laboratory is always obtained in the inactive form is in itself of no great significance. As has been already stated, the result is just what one would expect. It assumes its significance, however, when taken in conjunction with the fact that an asymmetric compound occurring in nature, with very rare exceptions, exists in the active form. In other words, it is the difference between the results of the laboratory synthesis and those of nature that impart to this general subject its remarkable interest.

The view that the production of the active forms of asymmetric compounds is characteristic of living organisms was advanced first by Pasteur. The following quotations are taken from his lecture delivered before the Chemical Society of Paris in 1860 .

All artificial bodies and all minerals have superposable images. Opposed to these are many organic substances (I might say nearly all, if I were 
to specify only those which play an important rôle in plant and animal life) all of which are important substances to life, are asymmetric, and indeed have the kind of asymmetry in which the image is not superposable with the object. ... When I assert that no artificial substances with molecular asymmetry are known, I speak of artificial substances in the proper sense of the word, which are formed in all their parts from the elements, or are produced from bodies which are not asymmetric. ... In this way the idea of the influence of the molecular asymmetry of natural organic products is introduced into physiological studies; this important characteristic is perhaps the only distinct line of demarkation which we can draw to-day between dead and living nature.

This view originally advanced by Pasteur is now so firmly established that no chemist would hesitate to take it into consideration in determining the origin of naturally occurring products. For example, it is a well-known fact that certain mineral oils found in nature are optically active and Walden, Engler and other investigators have contended that because of this property, these oils must be regarded as of organic rather than mineral origin.

The question that concerns us, however, is whether this inability to reproduce in the laboratory the results which are obtained in the living organism is due to a complete difference between the methods of the laboratory and those of nature, or whether it is due simply to lack of knowledge as to the conditions necessary for effecting the synthesis. It is evident that Pasteur inclined to the latter belief. In one of his lectures, after emphasizing that only the dextro or levo forms are produced in nature, he adds :

But why right and left molecules, why not only symmetrical molecules like those of the inorganic substances? There are certainly causes for this remarkable behavior of the molecular forces, even though it is difficult for us to get a clear conception of them. I believe that I am not deceived when I assert that we now know one of its most important characteristics. Is it not necessary and also sufficient to assume that the instant the plant organism arises an asymmetric force is active?
For we have seen above that the dextro-molecule deviates from its levo-antipode only in those cases in which it is subjected to some kind of an asymmetric action. Do such asymmetric agencies arise from the cosmic influences, light, electricity, magnetism, heat? Do they perhaps stand in close relation with the earth movements, with the electric current by means of which physicists explain the earth's magnetic pole.

Pasteur put his beliefs to the test by attempting to bring about asymmetric syntheses through the agency of the magnetic field as well as of polarized light.

It is evident that nature may act in one of two ways in building up active forms. In the first place asymmetric forces may be present of which we have no knowledge, through whose influence a single active form may be built up; or both of the active forms may result just as in our laboratory synthesis but, through some agency unknown to us, one of these forms may be used up by the organism or destroyed as fast as formed. The latter view is the one most generally accepted. Attention was called to the plausibility of this view by Fischer in a lecture delivered before the German Chemical Society in 1890. In this lecture after calling attention to the fact that only the active sugars of the dextromannite series are found in plants, Fischer adds :

Are these the only products of assimilation? Is the preparation of optically active substances a prerogative of the living organism? Is there brought into action here a special cause, a kind of life force? I think not, and incline much more to the view that only the incompleteness of our knowledge imparts to such processes the appearance of the miraculous.

No known facts are opposed to the view that the plant, just as in chemical synthesis, produces at first both forms, that it then separates the two and that it uses the members of the $d$-mannite series for the formation of starch, cellulose, inulin, etc., while the optical isomers serve for some other yet unknown purpose.

While Fischer's explanation may appear plausible, nevertheless the fact that no 
complete asymmetric synthesis has as yet ever been accomplished, notwithstanding the repeated efforts of many of our most skilful workers, has led some scientists to the belief that the problem does not admit of solution; that there exists in the organism some vital force or agency which directs the manner of combination of the atoms in the molecule and that this force is not reproducible in the laboratory. Such scientists, therefore, find in the facts of asymmetric syntheses an argument in support of the doctrine of vitalism-that doctrine which postulates that life is not the result of physical and chemical forces merely, but that these forces are guided through the directing agency of some vital force that comes into action with the life of the organism.

The advocates of the doctrine of vitalism criticize the assumption of Fischer cited above, on the ground that the destruction of one of the forms of an asymmetric compound partakes just as much of the miraculous as does the production of one of the forms alone; for with one possible exception the methods for accomplishing the separation require the use of already existing optically active substances. The exception referred to is the mechanical method, which is applicable, however, only when the two forms are solid compounds and separate from their solutions in crystals that are related to each other as object to image-a property which is possessed by the salts of the racemic tartaric acid. In all such cases it is readily possible to separate the two forms from each other mechanically, as Pasteur did in his original discovery. The opponents of the doctrine of vitalism hold that this constitutes a complete asymmetric synthesis; that starting with inactive substances, optically active forms have been obtained separate from each other without the use of previously existing optically ac- tive compounds, and without in any way employing the agency of life. To the vitalist, however, the action of the investigator in separating the two forms of crystals from each other is exactly similar to the action of an enzyme which destroys the one form and leaves the other in a pure state. This view is expressed by Professor Japp as follows:

It requires the living operator, whose intellect embraces the conception of opposite forms of asymmetry, to separate them (i. e., the two forms of crystals). Such a process can not, by any stretch of language, be termed "mechanical." Conscious selection here produces the same result as the unconscious selection exercised by the microorganism, the enzyme, or the previously existing asymmetric compound. . . . Only the living organism with its asymmetric tissues, or the asymmetric products of the living organism, or the living intelligence with its conception of asymmetry, can produce this result. Only asymmetry can beget asymmetry.

I can give no better summation of the views of the opposite schools of thought in regard to the bearing of the subject of asymmetric syntheses upon the doctrine of vitalism than to sum up briefly the main arguments advanced by Professor Japp in an address delivered before the British Association in 1898, as well as the arguments advanced by those who criticized the address. This latter number includes such eminent scientific men as Pearson, Spencer, Frankland, Armstrong, Fitzgerald, Errara, Kipping and Pope.

Japp bases his arguments largely upon the fact that all attempts to effect asymmetric syntheses without the intervention of life either directly or indirectly, have been futile. Neither does he think our failure to do so is due to "a temporary disability which the progress of science may remove." He calls attention to the fact that all the methods that have been used for separating a racemic form into its active constituents employed living agencies either directly or 
indirectly. He likewise emphasizes the fact that all attempts to utilize the magnetic field and polarized light have met with failure and concludes that even if an asymmetric force were to be discovered it could not lead to the production of a single form of an asymmetric compound.

No fortuitous concourse of atoms, even with all eternity for them to clash and combine in, could compass this feat of the formation of the first optically active organic compound. . . . But the chance synthesis of the simplest optically active compound from inorganic materials is absolutely inconceivable. So also is the separation of two erystallized enantiomorphs under purely symmetric eonditions. ... I see no escape from the conclusion that, at the moment when life first arose, a directive force came into play-a force of preeisely the same character as that which enables the intelligent operator, by the exercise of his Will, to select one crystallized enantiomorph and reject its asymmetric opposite.

Pearson dissents strongly from Japp's view that "the chance synthesis of the simplest optically active compound from inorganic materials is absolutely inconceivable." Japp had likened the result of the process whereby the dextro and levo forms of an asymmetric compound are produced from inorganic or symmetrical materials, to the tossing of a coin. If the coin is a perfectly balanced one the chances are equal as to whether it falls heads or tails; so in the synthesis of an asymmetric compound the chances are equal for the production of the two possible forms. Pearson argues, however, that if one will toss a coin (say) twenty times that while the results in general will be ten heads and ten tails, nevertheless there will be a variation from this mean; and that if the act of tossing were to be continued an infinite number of times one might come to an instance of twenty heads or twenty tails. So in the synthesis of the dextro and levo forms of an asymmetric compound, any action which gives rise to them, carried on through the ages, must produce the two forms in unequal amounts and the form in excess would then act as "breeders" in building up other asymmetric forms.

Fitzgerald argues that life probably originated from a few centers and possibly a single center. In the former case the chances are that either the dextro or the levo form predominated, so that asymmetry might have resulted, while in the latter case asymmetry must have resulted.

Herbert Spencer in criticizing the attitude of Japp states that he does so not "for the purpose of showing the adequacy of the physico-chemical interpretation of life, but for the purpose of showing the inadequacy of Professor Japp's argument against it." Spencer insists that, even granting that the dextro and levo forms of protein were formed originally in equal numbers these would not remain mixed together, but that their separation would follow in accordance with a universal law to the effect that unlike units, when acted upon by the same forces, are affected differently and that ultimately this difference will result in the segregation of the like units; in other words, the dextro and levo forms would in the course of time separate into the two groups of like molecules.

Others criticize Japp's statement to the effect that the right- and left-handed crystals can not be separated except through the agency of life. They think it quite possible for such a separation to have been brought about by ordinary natural agencies.

Thus Bartrum holds that it is entirely conceivable that the two forms of crystals on separation might be unevenly grouped, and that conditions might change so that partial solution would take place in which the one set of crystals might be more favorably situated than the other, and that the resulting solution would then be optically active. 
Errara thinks that the facts can be explained upon the assumption that the two forms generated somewhere in space, were separated by being whirled around through space, and that one of these forms reached the earth. From this all other asymmetric compounds might have originated.

Kipping and Pope give the results of experiments which prove that a single set of crystals deposited from a solution of a racemic compound is not always composed of equal amounts of the two forms, in which case not only the crystals, but the mother liquor as well, are optically active. Conditions here which give rise to the optically active substances are such as might exist in a purely inorganic world.

Professor Japp in his arguments in favor of vitalism was at a disadvantage in that his position upon the question compelled him to assume the attitude of one who denies the possibility of future advancement. He not only had to contend that none of the methods proposed would lead to an asymmetric synthesis, but that no methods ever would be discovered that would lead to such a synthesis. This latter position is a rather hazardous one to assume in these days of scientific advancement, in which the impossibilities of the one decade become the realities of the next. Aside from this attitude, the vulnerable point in Japp's position is the statement "that the chance synthesis of the simplest optically active compound from inorganic materials is absolutely inconceivable." It was against this view that most of the criticism was launched. In the subsequent discussion Japp admitted, indirectly at least, that this statement was perhaps too strong, for he adds that "all my critics seem to be moving in that unreal world where a font of type if jumbled together sufficiently often ends by setting up the text of Hamlet"-to which Frankland replies that if the font of type were jumbled an infinite number of times, the text of Hamlet must result.

Stewart has also called attention to another possible explanation for the generation of optically active forms in nature. Cotton (1896) proved that the two forms of copper ammonium tartrate absorb dextrocircularly polarized light unequally-a difference which would tend to favor the generation of the one form over the other in the presence of such light. Byk (1904) has shown that light is circularly polarized by reflection from water of the sea. Stewart finds in the combined observations of Cotton and Byk a satisfactory explanation for the presence in nature of optically active forms.

It is evident from the mere fact that Professor Japp's contention aroused such a series of discussions, and that these discussions apparently only served to strengthen the attitude of each of the participants in his original belief, that the facts of asymmetric syntheses can not be regarded as giving evidence at all conclusive in favor of the doctrine of vitalism. On the other hand, it must be admitted that the opponents of the doctrine have advanced no conclusive arguments in opposition to it. For while it is possible to imagine conditions under which asymmetric groups might have arisen in a purely inorganic world, nevertheless, such an argument may have little weight. To carry conviction the conditions for producing such groups must not only be possible; they must also lie within the bounds of probability. Whether or not the conditions assumed by Japp's critics to account for the production of the first asymmetric groups from inorganic materials, are probable conditions, is a question upon which there would undoubtedly be a difference of opinion. I am sure, however, that all of us would agree that some 
of the assumptions made are not very plausible.

At first thought, one might conclude that, with the problem of asymmetric syntheses as with the problem of life itself, the main difficulty is to account for the initial step. Given the unit living cell, all others might have developed from this; likewise given the unit asymmetric group, this might serve as the "seed" from which all the countless forms that exist in nature may have sprung. Granting, however, that the formation of the original asymmetric group or groups is satisfactorily explained, another perplexing question at once presents itself. For with perhaps a single exception, in all the partial asymmetric syntheses effected in the laboratory, both forms have been produced. In other words, the best we can do is to synthesize the one form in excess of the other and as a rule this excess is only slight. On the other hand, out of all the infinite variety of optically active compounds found in nature, only in very rare instances are both forms found. Ordinary lactic acid, produced by the fermentation of lactose, contains both forms, although in slightly unequal amounts: $d l$-limonene (dipentene) occurs in certain turpentine oils, while levoasparagine is found in some plants along with small amounts of the dextro compound. In the laboratory, therefore, the production of both forms is the almost invariable rule; in nature it is the marked exception. To explain this difference upon the assumption that the methods of nature like those of the laboratory lead to the synthesis of both forms, one of which is destroyed as fast as generated, is, in the light of our present knowledge, quite as unsatisfactory as is the assumption that one form only is produced.

The assumption that there exists in the living organism a vital or guiding force which directs the changes that take place within the organism has never been a popular one among chemists. It is fortunate that this is so, for to accept such a belief would be to destroy the spirit of investigation, so far as it applies to a study of many of the problems connected with the living organism. However, the chemist, familiar with the wonderful results that may be accomplished through the action of chemical forces and recognizing that as yet we have but little insight into the nature of these forces, is apt to ascribe to them powers that can not be justified in the light of the knowledge at hand.

The discovery of Wöhler that urea can be synthesized in the laboratory was of the greatest importance; but neither the synthesis of urea nor the synthesis of any other of the almost countless number of compounds effected in the laboratory actually disproves the existence of a vital force in the living organism. Likewise it is certain, to my mind at least, that while the facts of asymmetric synthesis, so far as we can discern at the present time, do not prove the existence of such a force in the living organism, neither do they present any valid argument against the belief in its existence. So far as they have a bearing upon the question, life remains as it always has been-the great mystery.

\section{OHio State University, CoLumbus, Оніо}

\section{SCIENTIFIC EVENTS}

MINUTE ON THE LIFE AND SERVICES OF HUGO MÜNSTERBERG

THE following minute on the life and services of Professor Hugo Münsterberg was placed upon the records of the faculty of arts and sciences of Harvard University at the meeting of January 16, 1917:

Hugo Münsterberg, professor of psychology, died in Cambridge on the sixteenth of December, 1916. He was born in Danzig, West Prussia, June 1, 1863. After leaving the gymnasium in his native 